\title{
Repression of Fanconi Anemia Gene (FACC) Expression Inhibits Growth of Hematopoietic Progenitor Cells
}

\author{
Gerald M. Segal, R. Ellen Magenis, Michael Brown, Winifred Keeble, Tamara D. Smith, Michael C. Heinrich, \\ and Grover C. Bagby, Jr. \\ Division of Hematology and Medical Oncology, Department of Medicine, Oregon Health Sciences University, and Veterans Affairs \\ Medical Center and the Department of Medical Genetics, Oregon Health Sciences University, Portland, Oregon 97201-3098
}

\begin{abstract}
Bone marrow failure is a consistent feature of Fanconi anemia (FA) but it is not known whether the bone marrow failure is a direct and specific result of the inherited mutation or a consequence of accumulated stem cell losses resulting from nonspecific DNA damage. We tested the hypothesis that the protein encoded by the $\mathrm{FA}$ group $\mathrm{C}$ complementing gene $(F A C C)$ plays a regulatory role in hematopoiesis. We exposed normal human lymphocytes, bone marrow cells, endothelial cells, and fibroblasts to an antisense oligodeoxynucleotide (ODN) complementary to bases -4 to +14 of FACC mRNA. The mitomycin $\mathrm{C}$ assay demonstrated that the antisense ODN, but not missense or sense ODNs, repressed $F A C C$ gene expression in lymphocytes. Treatment with the antisense ODN substantially reduced, in a sequence-specific fashion, cytoplasmic levels of FACC mRNA in bone marrow cells and lymphocytes. Escalating doses of antisense ODN increasingly inhibited clonal growth of erythroid and granulocyte-macrophage progenitor cells but did not inhibit growth of fibroblasts or endothelial cells. The antisense ODN did not inhibit growth factor gene expression by low density bone marrow cells or marrow-derived fibroblasts. We conclude that, while the FACC gene product plays a role in defining cellular tolerance to cross-linking agents, it also functions to regulate growth, differentiation, and/or survival of normal hematopoietic progenitor cells. (J. Clin. Invest. 1994. 94:846-852.) Key words: hematopoiesis • antisense oligonucleotides - DNA damage • chromosome instability - cross-linking agent
\end{abstract}

This work was presented in part at the Clinical Research meetings (AAP/ASCI/AFCR) on 3 May 1993 in Washington, D.C. (1993. Clin. Res. 41:276A) and at the American Society of Hematology Annual Meeting on 6 December 1993 in St. Louis, MO (1993. Blood. 82 [Suppl. 1]:183a).

Address correspondence to Gerald M. Segal, M.D., Division of Hematology and Medical Oncology-L580, Oregon Health Sciences University, 3181 S.W. Sam Jackson Park Road, Portland, OR 972013098.

Received for publication 2 December 1993 and in revised form 22 April 1994.

The Journal of Clinical Investigation, Inc.

Volume 94, August 1994, 846-852

\section{Introduction}

Fanconi anemia (FA) ${ }^{1}$ is an autosomal recessive disorder characterized by cellular hypersensitivity to agents that damage DNA, bone marrow failure, diverse congenital anomalies, and a marked increase in the incidence of acute myelogenous leukemia $(1,2)$. Diagnostically, the sine qua non of this disorder is hypersensitivity of FA cells to the clastogenic effects of DNA cross-linking agents such as diepoxybutane and mitomycin $\mathrm{C}(3,4)$. This disorder is genetically heterogeneous, with four different complementation groups having been identified by somatic cell hybrid analysis (5). While the cDNA for group $\mathrm{C}$ has been cloned, sequenced, and mapped to chromosome $9 q 22.3(6,7)$, there is no substantial amino acid sequence homology with any known gene family and, to date, the function of the gene product is unknown (6). This is particularly true for the potential role of the FACC protein in hematopoiesis. Clearly, the FACC gene product functions to either facilitate interstrand cross-link repair (directly or indirectly) (8) or to inhibit naturally occurring factors that enforce DNA damage caused by crosslinking agents. The capacity of mutations in this gene to predispose to cell damage confounds studies on hematopoiesis. Specifically, aberrancies of in vitro growth, differentiation, or survival found in progenitor cells from children with FA might derive either from nonspecific cell damage or, more directly, from mutation of $F A C C$ if the FACC protein plays a direct role in hematopoiesis.

Because the use of randomly damaged cell populations can be avoided by studying normal somatic cells, a genetic loss-offunction approach to the analysis of FA cells is a more promising strategy. The recent characterization of the FACC gene (6, 7 ) and the formal demonstration that the inherited mutation is sufficient to confer the mitomycin $\mathrm{C}$-sensitive phenotype (9) have enabled us to test directly the hematopoietic activity of the FACC gene product using specific antisense oligonucleotides. These studies were designed to test the hypothesis that the FACC gene product plays a direct permissive role in growth and/or differentiation of hematopoietic progenitor cells.

1. Abbreviations used in this paper: BFU-E, burst-forming unit erythroid; CFU-E, colony-forming unit erythroid; CFU-GM, CFU granulocyte/macrophage; FA, Fanconi anemia; FACC, Fanconi anemia group C complementing gene; GAPDH, glyceraldehyde-3-phosphate dehydrogenase; ODN, oligodeoxyribonucleotide; RT, reverse transcription. 
Table I. Effect of FACC Gene Repression on Chromosomal Aberrations in Normal Lymphocytes

\begin{tabular}{clccc}
\hline Mitomycin C & ODN & $\begin{array}{c}\text { Radials } \\
\text { (per 100 cells) }\end{array}$ & $\begin{array}{c}\text { Percentage of cells } \\
\text { with no breaks }\end{array}$ & $\begin{array}{c}\text { Breaks } \\
\text { (per 100 cells) }\end{array}$ \\
\hline None & None & 0 & $97 \pm 3$ & $1.5 \pm 1.5$ \\
None & AS & 0 & 100 & 0 \\
None & S/MS & 0 & 100 & 0 \\
+ & None & $14 \pm 4$ & $44 \pm 11$ & $48 \pm 5$ \\
+ & AS & $34 \pm 2^{*}$ & $14 \pm 1 *$ & $136 \pm 18^{*}$ \\
+ & S/MS & 10 & $44 \pm 1$ & $67 \pm 18$
\end{tabular}

* In the presence of mitomycin $\mathrm{C}$, values for all three antisense $(A S)$ scores (columns 3-5) were significantly different than values for the None and S/MS rows $(P<0.05)$.

\section{Methods}

Oligonucleotides. The antisense 18-mer we used was selected after examination of the predicted secondary structure of the FACC transcript (RNAFOLD, State Line, PA), so that potentially stable intramolecular stem structures in the target FACC mRNA were avoided. This 18-mer sequence itself was not complementary to any other sequence in GenBank or EMBL, or to itself, and did not form a stable intrastrand stem structure. All oligodeoxyribonucleotides (ODNs) were 18-mers: AS, antisense FACC (5'-GAATCTTGAGCCATCTTG-3' [ complementary to bases -4 to +14 relative to the translation initiation site ]); $\mathrm{S}$, sense FACC ( 5 '-CAAGATGGCTCAAGATTC-3' [ bases -4 to +14]); MS, missense (5'-TAGGATACGCATTAAATC-3' [ five point mutations were inserted in GM-CSF cDNA covering bases +1 to +18$]$ ). Neither the sense nor missense ODNs influenced mitomycin $C$ sensitivity so the results for these sequences are pooled in Table I. ODNs were synthesized by phosphoramadite chemistry with a DNA synthesizer (model 391; Applied Biosystems, Foster City, CA) and purified on Nensorb Prep columns (New England Nuclear, Boston, MA).

Mitomycin $C$ assay. Human peripheral blood mononuclear leukocytes were isolated from normal volunteers using centrifugation on Ficoll-Hypaque (Pharmacia LKB Biotechnology Inc., Piscataway, NJ) as described previously (10) and resuspended at a concentration of 4.0 $\times 10^{6} \mathrm{cells} / \mathrm{ml}$. Ficoll-Hypaque-separated lymphocytes from two normal volunteers ( 50 and $24 \mathrm{yr}$ of age) were cultured in a microwell culture plate in $1 \mathrm{ml}$ of RPMI 1640 medium supplemented with $10 \%$ "high-heat" inactivated $\left(45 \mathrm{~min}\right.$ at $66^{\circ} \mathrm{C}$ to efficiently inactivate DNases known to degrade ODNs in vitro [11]) FCS (Hyclone Laboratories, Logan, UT ), $4 \mu \mathrm{M}$ L-glutamine, and $1 \%$ phytohemagglutinin. Antisense, missense, and sense ODNs ( $20 \mu \mathrm{M})$ were added to different wells at the same time mitomycin $\mathrm{C}$ was added according to methods described previously (12). In certain experiments, total cytoplasmic RNA was extracted $6 \mathrm{~h}$ after the addition of ODNs (see below). After $4 \mathrm{~d}$, metaphase preparations (13) were made, and viable cell counts were performed using a hemocytometer and trypan blue staining. 50 (donor 1 ) or 100 (donor 2) metaphases were scored (for breaks and radial forms) for each experimental condition. A radial was defined as a chromatid interchange, in which chromatids remained paired in mitosis, giving rise to a structure with multiple arms.

Treatment of bone marrow cells with ODNs. Paid normal human volunteers, after having given signed informed consent, provided bone marrow cells from the iliac crest. In certain experiments, low density bone marrow mononuclear cells (14) were depleted of adherent cells and $\mathrm{T}$ lymphocytes as described previously (14) or were enriched for $\mathrm{CD} 34^{+}$cells using an immunoaffinity column (Ceprate ${ }^{\mathrm{TM}} \mathrm{LC}$; CellPro, Inc., Bothell, WA ). To determine the percentages of $\mathrm{CD} 34^{+}$cells present before and after enrichment, the cells were stained with either an
FITC-conjugated anti-human CD34 murine monoclonal antibody (QBEND10 [IgG1]; Amac, Inc., Westbrook, ME) or an FITC-conjugated control IgG1 murine monoclonal antibody (IgG1/ZX3; Exalpha, Boston, MA), washed extensively, fixed in $2 \%$ paraformaldehyde, and then analyzed by flow cytometry (FACScan ${ }^{\circledR}$; Becton Dickinson Immunocytometry Systems, Mountain View, CA $)$. The cells $\left(1 \times 10^{6}\right.$ low density cells or nonadherent T lymphocyte-depleted cells $/ \mathrm{ml}$ or $3 \times 10^{5}$ $\mathrm{CD} 34^{+}$cells $\left./ \mathrm{ml}\right)$ were incubated with or without ODNs $(20 \mu \mathrm{M})$ for $18 \mathrm{~h}$ in RPMI supplemented with $10 \%$ FCS which had been high-heatinactivated and recombinant human erythropoietin $(2 \mathrm{U} / \mathrm{ml}$; Amgen Biologicals, Thousand Oaks, CA). The cells were then recharged with ODNs $(20 \mu \mathrm{M})$ for an additional $6 \mathrm{~h}$ and were then used either in hematopoietic colony growth assays or for RNA isolation.

Isolation of RNA and reverse transcription PCR (RT-PCR) analysis. Total cytoplasmic RNA was extracted from ODN-treated and untreated PHA-stimulated peripheral blood mononuclear cells or low density bone marrow cells (see above) as described previously (11). First strand cDNA was reverse transcribed from $1 \mu \mathrm{g}$ of peripheral blood mononuclear cell RNA or $2 \mu \mathrm{g}$ of bone marrow cell RNA using random hexanucleotide primers (GIBCO BRL, Gaithersburg, MD) and MMLV RNase $\mathrm{H}^{-}$reverse transcriptase (GIBCO BRL) exactly as described previously (11). The cDNA was then amplified by PCR for 36 cycles (denature at $94^{\circ} \mathrm{C}$ for $30 \mathrm{~s}$, primer anneal at $53^{\circ} \mathrm{C}$ for $1 \mathrm{~min}$, primer extend at $72^{\circ} \mathrm{C}$ for $1 \mathrm{~min}$ ) as described previously (11). Control reactions, in which $1 \mu \mathrm{g}$ plasmid cDNA (see below) or no cDNA (i.e., only water) was added to the PCR mixture, were run with each experiment. The amplification products were separated by electrophoresis on $1.5 \%$ agarose, stained with ethidium bromide, and visualized with an ultraviolet transilluminator. The respective sense and antisense primers used for PCR, their locations relative to the translation start site, and the PCR amplification product sizes were as follows: $F A C C(6,7)$-GAAATCCTCCAGCCAGAGTTC (bases 638-658), CCCATCCTCCGAAGTGAATGA (1190-1210), 573 bp; glyceraldehyde-3-phosphate dehydrogenase (GAPDH) (15)-CCACCCATGGCAAATTCCATGGCA (148-171), TCTAGACGGCAGGTCAGGTCCACC (722-745), 598 bp. A 4.6-kb NotI fragment containing the full-length FACC cDNA was isolated from pREP4 FAC3 (6), cloned into the NotI site of pGEM $13 Z$ (Promega Corp., Madison, WI), and used as a positive FACC control for PCR. The positive GAPDH control for PCR is a 5.6-kb plasmid construct (American Type Culture Collection, Rockville, MD) containing a 1.2-kb GAPDH cDNA insert (15).

Hematopoietic colony growth assays. Bone marrow cells were cultured $(14)$ in $1-\mathrm{ml}$ volumes $\left(1 \times 10^{5}\right.$ low density cells, $5 \times 10^{4}$ nonadherent $\mathrm{T}$ lymphocyte-depleted cells, or $5 \times 10^{2} \mathrm{CD} 34^{+}$cells $\left./ \mathrm{ml}\right)$ in Iscove's modified Dulbecco's medium made semisolid with $1 \%$ methylcellulose and supplemented with $30 \%$ FCS, $1 \%$ deionized bovine serum albumin (Sigma Immunochemicals, St. Louis, MO), $2 \mathrm{mM} \mathrm{L-glutamine,}$ $10^{-4} \mathrm{M} \beta$-mercaptoethanol, penicillin-streptomycin, and recombinant human growth factors (colony-forming unit erythroid [CFU-E]: erythropoietin $2 \mathrm{U} / \mathrm{ml}$; burst-forming unit erythroid [BFU-E] and colonyforming unit granulocyte/macrophage [CFU-GM]: IL-3 [R \& D Systems, Minneapolis, MN] $1 \mathrm{ng} / \mathrm{ml}$, G-CSF [Amgen Biologicals] $100 \mathrm{U} /$ $\mathrm{ml}$, and erythropoietin $2 \mathrm{U} / \mathrm{ml}$; Steel factor [Amgen Biologicals] 100 $\mathrm{ng} / \mathrm{ml}$ was also added to the cultures of $\mathrm{CD} 34^{+}$cells.). CFU-E-derived colonies or erythroid bursts and GM colonies were enumerated after 7 or $14 \mathrm{~d}$, respectively, in culture. Extracellular ODNs were not present in the clonal assays because the FCS used in methylcellulose cultures was not high-heat inactivated, and consequent ODN degradation occurs within $3 \mathrm{~h}$ (11). Colony growth results were expressed as mean colony numbers of triplicate or five replicate cultures. $P$ values (unpaired Student's $t$ test ) for each ODN were determined relative to untreated cells.

Endothelial cell and fibroblast growth. 11-Lu diploid human fibroblasts (American Type Culture Collection) and human foreskin fibroblasts (NFF6) were grown to confluence in Eagle's MEM with $10 \%$ FCS. Cells were harvested and plated at $10 \%$ confluence in multiple 24-well plastic tissue culture plates in the same medium containing highheat-inactivated FCS with or without ODNs, or in complete medium 
containing either high-heat-inactivated FCS or low-heat-inactivated serum $\left(56^{\circ} \mathrm{C}\right)$ without ODNs. Cells were cultured for up to $7 \mathrm{~d}$. Cells were harvested regularly from duplicate wells using light trypsinization, and trypan blue viable cell counts were performed in a hemocytometer. Human bone marrow fibroblasts, prepared as described previously from low density bone marrow cells (16), were grown to confluence before the study. Half of the confluent cells were exposed to IL- $1 \alpha$, with and without antisense, sense, and missense FACC ODNs, and the remainder was exposed to medium alone with and without ODNs.

Human umbilical vein endothelial cells were obtained according to techniques described previously $(10,14,17,18)$ and cultured in RPMI 1640 medium supplemented with $20 \%$ FCS, heparin, and endothelial cell growth factor (19). Cells were passaged continuously on $25-\mathrm{cm}^{2}$ plastic tissue culture flasks coated with $0.1 \%$ gelatin (Sigma Immunochemicals). Eighth passage cells in 24-well tissue culture plates were exposed for $18 \mathrm{~h}$ to ODNs in medium supplemented with $20 \%$ highheat-inactivated FCS, after which complete medium with low-heatinactivated FCS was substituted. Cells were lifted from the wells $7 \mathrm{~d}$ later for viable cell counts as described above for fibroblasts.

Hematopoietic growth factor assays. Low density bone marrow cells or bone marrow fibroblasts were incubated for $2 \mathrm{~d}$ in RPMI 1640 with $10 \%$ high-heat-inactivated FCS. Half of the cultured cells were exposed to $1 \mathrm{ng} / \mathrm{ml}$ recombinant human IL- $1 \alpha$ (kindly provided by Dr. Peter LoMedico, Hoffman-LaRoche, Nutley, NJ). The cultured cells were exposed to sense, antisense, or no ODNs. Sense and antisense.ODNs $(20 \mu \mathrm{M})$ were added to the cultures first, and IL-1 was added $60 \mathrm{~min}$ later. GM-CSF, IL-6, and G-CSF (18) assays (sandwich ELISA assays; $R$ \& D Systems) were performed on supernatants of these cultures. Supernatants of ODN-exposed low density marrow cells were also tested for the presence of colony growth inhibitory factors by including aliquots of these supernatants $(10 \% \mathrm{vol} / \mathrm{vol})$ in methylcellulose cultures of marrow cells that had not been exposed to ODNs.

\section{Results}

Antisense ODN represses FACC expression. To validate the capacity of the antisense sequence to repress $F A C C$ gene expression, lymphocytes from two normal volunteers were tested in the mitomycin $\mathrm{C}$ assay before and after exposure to $20 \mu \mathrm{M}$ antisense (FACC), missense, or sense (FACC) oligonucleotides. In both cases, the antisense oligonucleotide resulted in: $(a)$ increased breaks per 100 metaphases; $(b)$ increased radial formation; and $(c)$ a reduction in the fraction of metaphases that were free of aberrations (Fig. 1 and Table I). Exposure of cells to the control oligonucleotides had no such effect ( Table I).

We also examined, by RT-PCR analysis, the effect of exposure to the antisense ODN on FACC mRNA levels in low density bone marrow mononuclear cells or PHA-stimulated peripheral blood mononuclear cells. As shown in Fig. 2, treatment for $24 \mathrm{~h}$ with the FACC antisense ODN substantially reduced FACC mRNA levels in bone marrow cells. In contrast, the sense ODN had no effect on FACC mRNA expression. Similarly, exposure to the FACC antisense ODN for only $6 \mathrm{~h}$ reduced FACC mRNA levels in peripheral blood lymphocytes to $63 \%$ of the levels of cells not exposed to ODN, while treatment with the sense ODN did not alter FACC mRNA levels (data not shown). Neither ODN affected GAPDH expression in marrow cells (Fig. 2) or peripheral blood cells (not shown).

Antisense $O D N$ inhibits $C F U-E_{-}, B F U-E_{-}$, and $C F U-$ $G M-$ derived colony growth. Bone marrow cells from six normal volunteers were exposed to multiple doses of antisense and sense ODNs for $24 \mathrm{~h}$ and were then replated in methylcellulose in the presence of hematopoietic growth factors. Exposure of marrow cells to the antisense molecule specifically, significantly, and in a dose-related fashion inhibited clonal growth of erythroid (CFU-E and BFU-E) and myeloid (CFU-GM) progenitor cells (Fig. 3). Phosphorothioate-modified oligonucleotides were also used in some experiments, the antisense versions (but not the sense strands) of which effected equivalent suppression of clonal growth (not shown). Although some investigators have observed that exposure of FA cells to atmospheric oxygen or hyperoxia inhibits growth in vitro (20-22), parallel culture studies performed at both 0.1 or 5 and $20 \% \mathrm{O}_{2}$ indicated that the gene product is required for optimal colony growth at all oxygen tensions (not shown).

The inhibitory effect of the antisense ODN was noted on bone marrow cells depleted of adherent cells and $\mathrm{T}$ lymphocytes (Table II). Likewise, pretreatment with the antisense ODN inhibited BFU-E- and CFU-GM-derived colony growth from bone marrow cells which had been highly enriched for cells expressing the integral membrane protein CD34 (the proportion of $\mathrm{CD} 34^{+}$cells before and after enrichment was 4.1 and $69.7 \%$, respectively $)$ and then cultured at very low cell density $\left(5 \times 10^{2}\right.$ cells/ml, Table II). CFU-E-derived colony growth was not observed in the cultures of $\mathrm{CD} 34^{+}$cells (Table II), consistent with the observation that CFU-Es do not express CD34 (23).

Antisense ODN does not suppress growth factor gene expression. Our observations with hematopoietic progenitor cellenriched marrow cell populations (Table II) are compatible with the view that the antisense ODN directly inhibited progenitor cell replication and/or differentiation. However, some auxiliary cells usually contaminate even highly enriched progenitor cell populations from human marrow. Therefore, the suppression of clonal hematopoiesis also might have resulted from functional inhibition of the few colony-stimulating factor-producing auxiliary cells that remained in these cultures. Therefore, we tested this notion directly by measuring constitutive and IL1 -induced synthesis of GM-CSF, G-CSF, and IL- 6 by human low density bone marrow cells or bone marrow fibroblasts cultured with and without ODNs. We chose to assay these three factors because they enhance clonal growth of progenitor cell types examined in this study. Neither sense nor antisense sequences inhibited uninduced or IL-1-induced growth factor gene expression (Table III). In addition, we did not detect soluble inhibitors of clonal growth produced by antisense ODN-treated marrow cells (not shown). Taken together with our findings with progenitor cell-enriched marrow cells (Table II), our results suggest that the antisense molecules inhibit hematopoiesis by directly inhibiting clonal growth or differentiation of progenitor cells rather than by inhibiting growth factor production.

Antisense ODNs do not inhibit fibroblast, lymphocyte, or endothelial cell growth in vitro. Diploid fibroblasts were also exposed to multiple doses of ODNs for $24 \mathrm{~h}$, after which complete medium was replaced, and cells were cultured for up to $7 \mathrm{~d}$. None of the ODNs inhibited replication of these cells. Fig. 4 represents results of studies on 11-Lu fibroblasts. Results in studies on NFF6 diploid fibroblasts and human umbilical vein endothelial cells were identical (not shown). None of the ODNs inhibited peripheral blood mononuclear cell growth assessed after $4 \mathrm{~d}$ of mitogen stimulation using the same culture conditions as were used for the mitomycin $\mathrm{C}$ test (not shown). We do not attribute the lack of an inhibitory effect to failure of the 


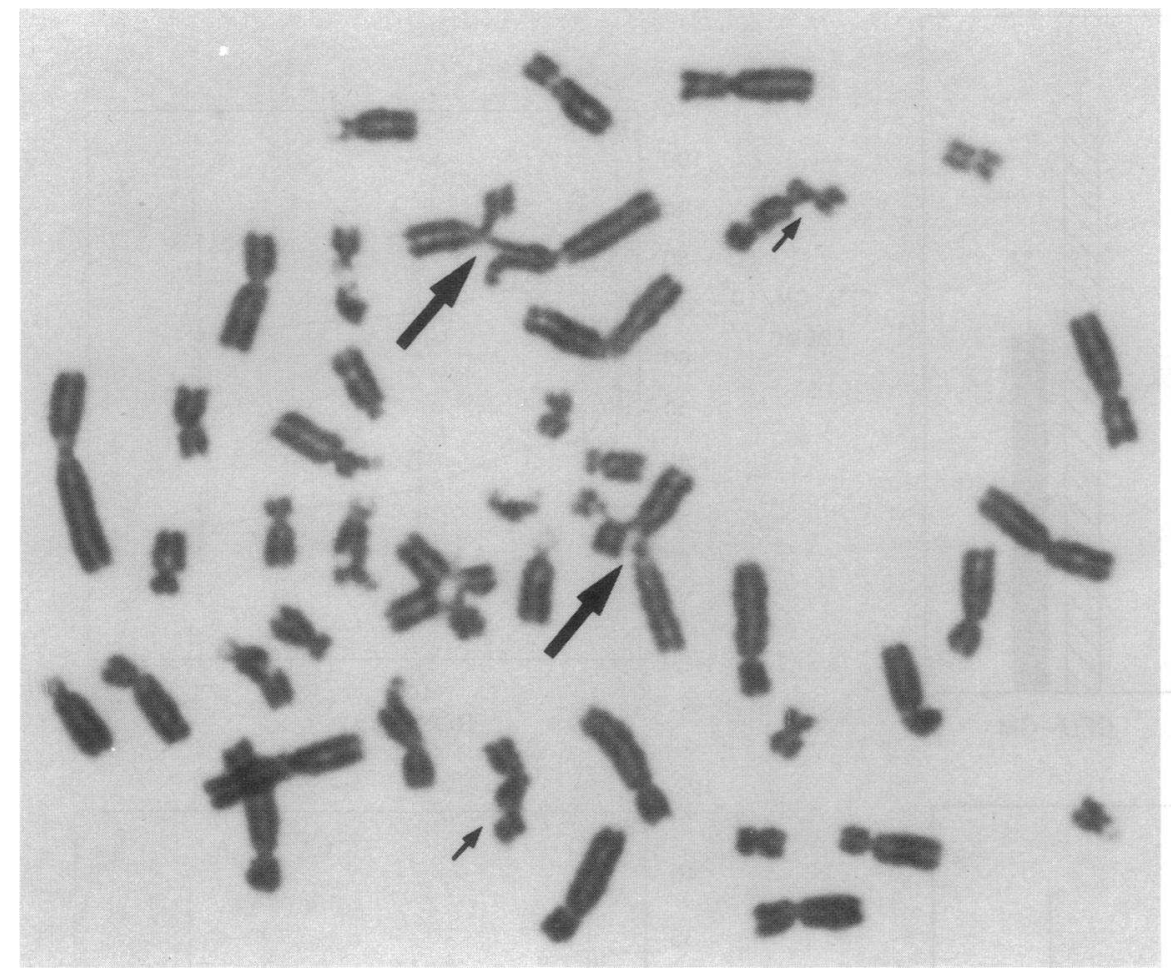

Figure 1. Radial forms and broken chromosomes result from exposure of normal lymphocytes to antisense FACC ODN, PHA, and mitomycin C. Radial forms (large arrows) and breaks ( small arrows) are similar to those seen in lymphocyte culture from Fanconi anemia patients treated with mitomycin C. Similar results were seen in experiments using lymphocytes from a second normal volunteer (Table I).
ODNs to enter or function within endothelial cells or fibroblasts because we have shown previously that antisense oligonucleotides are taken up by these cells and efficiently repress gene expression $(11,24)$.

\section{Discussion}

The nearly universal occurrence of bone marrow failure and the high risk of acute nonlymphocytic leukemia in children with FA $(2,25,26)$ suggest that hematopoietic tissue is uniquely sensitive to FA mutations. Clearly, the high frequency of cytogenetic defects in bone marrow cells of FA children with myelo-

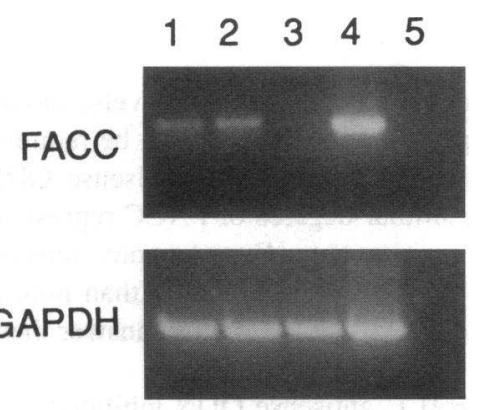

Figure 2. Sequence-specific reduction of cytoplasmic FACC mRNA levels in antisense ODN-treated low density bone marrow cells. The upper panel demonstrates the 573-base FACC amplification product of RT-PCR reactions using bone marrow cell RNA and FACCspecific primers. The lower panel shows the 598-base GAPDH amplification product using the same amount of mRNA with GAPDH-specific primers. Lane 1 , cells unexposed to ODN; lane 2, cells exposed to sense FACC ODN; lane 3, cells exposed to antisense FACC ODN; lane 4, plasmid containing FACC cDNA (upper panel) or GAPDH cDNA (lower panel); lane 5, no cDNA (i.e., only water) added to PCR mixtures. Molecular weight markers, run on the same gel, are not shown. dysplasia and acute leukemia $(26,27)$ confirms that acquired defects in somatic cells are an important element of multistep leukemogenesis, but the nature of early bone marrow failure in FA patients is unknown. Indeed, early marrow failure may represent a condition favoring the very earliest steps in leukemogenesis. To clarify the relationships that exist between bone marrow failure and leukemogenesis in this population of patients, the function of the FA gene product must be determined.

It is possible that bone marrow failure is only the result of nonspecific hematopoietic injury resulting from accumulated DNA damage. However, that the products of one or more of the FA complementing genes plays a regulatory role in growth of hematopoietic cells is also a plausible, albeit not necessarily exclusive, explanation. These alternatives cannot be tested by studying hematopoietic cells from patients with FA because any observed aberrancies might derive either from a specific (inherited) loss of hematopoietic function or from nonspecific damage to hematopoietic stem cells and/or bone marrow stromal cells that support hematopoiesis. Indeed, some stromal cell abnormalities have been described in FA cells, including abnormal production of hematopoietic growth factors (28-30), but it is likely that these are acquired because such defects are not consistently found in affected patients in multiplex families (30).

In this study, we have shown that pretreatment of normal lymphocytes with the FACC antisense ODN induces hypersensitivity to the chromosome-damaging effects of mitomycin $\mathrm{C}$ (Fig. 1 and Table I), in effect recapitulating the FA cytogenetic phenotype. The sequence-specific reduction of FACC mRNA levels in antisense ODN-treated bone marrow cells (Fig. 2) and mitogen-stimulated peripheral blood mononuclear cells (not shown) provides additional support for the notion that the antisense ODN specifically represses FACC gene expression in 

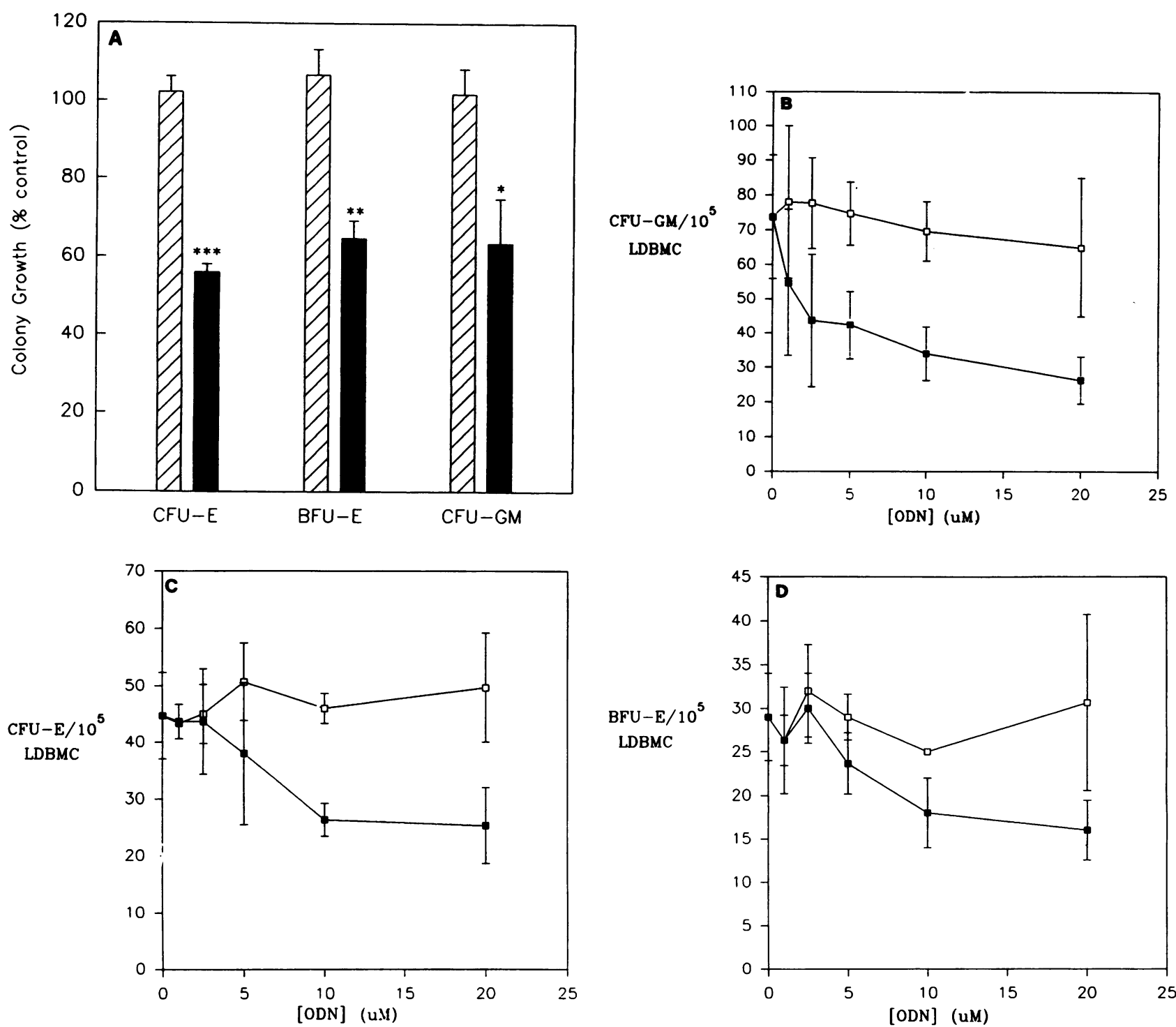

Figure 3. (A) Effect of FACC ODNs on CFU-E-, BFU-E-, and CFU-GM-derived colony growth in vitro. Results shown are mean \pm SD of six separate experiments. Antisense (black bars) but not sense (hatched bar in $A$ and white boxes in $B-D$ ) oligonucleotides inhibited clonal growth significantly $(P<0.001)$. The results have been normalized to colony growth in the absence of ODN treatment $(100 \%)$. Antisense ODN doserelated inhibition of clonal growth is shown for CFU-GM $(B)$, CFU-E $(C)$, and BFU-E $(D)$.

these cells, possibly by an RNase $\mathrm{H}$-dependent mechanism $(11,31,32)$. Pretreatment with the FACC antisense ODN inhibits clonal growth of erythroid and granulomonocytic progenitor cells in a concentration-dependent, sequence-specific fashion (Fig. 3). The apparently greater sensitivity of CFU-GM-derived colony growth (Fig. $3 \mathrm{~B}$ ), compared with CFU-E- and BFU-E-derived colony growth (Fig. 3, $C$ and $D$ ), could reflect inherent differences between the progenitor cell types in their relative sensitivity to similar degrees of FACC repression, the efficiency with which they internalize ODNs (33), their relative RNase $\mathrm{H}$ levels; or any of a number of other possibilities. An explanation for why inhibition of colony growth was only partial even at maximal ODN concentrations (Fig. 3) cannot be provided from the present study. Because, by design, exposure of marrow cells to the antisense ODN was brief in these experiments, it is likely that our protocol of ODN treatment only partially and transiently reduces FACC protein levels; further reduction in FACC protein for longer periods may be required to fully inhibit colony growth. Alternatively, antisense ODN treatment may not achieve similar degrees of FACC repression in all progenitor cells of a given type. For example, actively cycling cells may take up ODNs more efficiently than noncycling cells (34). Further study will be required to answer these questions.

Pretreatment with the FACC antisense ODN inhibited subsequent colony growth in cultures of progenitor-enriched marrow cells ( Table II), including a CD34 ${ }^{+}$cell-enriched population which displayed $\sim 9-10 \%$ plating efficiency even when cultured at very low cell density $(500$ cells $/ \mathrm{ml})$. Moreover, the FACC antisense ODN does not inhibit constitutive or IL-1induced GM-CSF, G-CSF, or IL-6 production by low density marrow cells or bone marrow-derived fibroblasts (Table III). 
Table II. Suppression of Colony Growth by the FACC Antisense Oligonucleotide in Cultures of Low Density Bone Marrow Cells (LDBMCs) Enriched for Hematopoietic Progenitors*

\begin{tabular}{lccc}
\hline \multicolumn{1}{c}{ ODN } & CFU-E & BFU-E & CFU-GM \\
\hline $\begin{array}{l}\text { Nonadherent T lymphocyte- } \\
\text { depleted LDBMCs }\end{array}$ & & & \\
None & $230 \pm 3$ & $127 \pm 11$ & $111 \pm 9$ \\
S & $255 \pm 22$ & $136 \pm 5$ & $96 \pm 15$ \\
AS & $110 \pm 7^{\ddagger}$ & $85 \pm 3^{8}$ & $54 \pm 3^{\| 1}$ \\
CD34 & & & \\
None & 0 & $21.8 \pm 5.3$ & $25.2 \pm 0.5$ \\
S & 0 & $23.8 \pm 2.4$ & $22.8 \pm 4.5$ \\
AS & 0 & $13.2 \pm 2.6^{\ddagger}$ & $13.6 \pm 3.2^{\ddagger}$ \\
& & & \\
\hline
\end{tabular}

* The results represent the mean $\left( \pm\right.$ SEM) of colonies per $5 \times 10^{4}$ nonadherent $\mathrm{T}$ lymphocyte-depleted LDBMCs per milliliter of triplicate cultures or $5 \times 10^{2} \mathrm{CD} 34^{+}$LDBMCs per milliliter of five replicate cultures. ${ }^{\ddagger} P<0.0001 ;{ }^{8} P<0.02$; and $\quad P<0.005$.

Taken together, these results suggest that antisense ODN-mediated inhibition of colony growth occurs via direct effects of the ODN on hematopoietic progenitor cells rather than on accessory cells.

The results of this study indicate that the FACC gene product plays a permissive role in growth, differentiation, or survival of hematopoietic progenitor cells. These observations suggest that hematopoietic progenitor cell defects in FA may arise not only from accumulated genetic damage in the stem cell or stromal cell (30) populations but develop because committed hematopoietic progenitor cells, and possibly stem cells, require the FACC gene product for optimal growth, survival, and/or differentiation. This notion is supported by gain-of-function studies of Walsh et al. (35) in which infection with a retroviral vector containing the normal human FACC gene complemented the cytogenetic defect and augmented clonal growth of CD $34^{+}$cells from the peripheral blood of a Fanconi anemia patient with a

Table III. Antisense FACC ODN Does Not Inhibit Production of the Hematopoietic Growth Factors IL-6, GM-CSF, and G-CSF

\begin{tabular}{lccccc}
\hline Cells & IL-1 & ODN & IL-6 & GM-CSF & G-CSF \\
\hline & $n g / m l$ & & $p g / m l$ & $p g / m l$ & $p g / m l$ \\
LDBMC & 0 & 0 & $1 \pm 1$ & 0 & 0 \\
LDBMC & 0 & S & $161 \pm 31$ & 0 & 0 \\
LDBMC & 0 & AS & $87 \pm 33$ & 0 & 0 \\
LDBMC & 1 & 0 & $192 \pm 38$ & $21 \pm 3$ & 0 \\
LDBMC & 1 & S & $818 \pm 91$ & $36 \pm 1$ & $43 \pm 16$ \\
LDBMC & 1 & AS & $768 \pm 49$ & $28 \pm 1$ & $35 \pm 13$ \\
F & 0 & 0 & $6758 \pm 1360$ & 0 & 0 \\
F & 0 & MS & $6838 \pm 1660$ & 0 & 0 \\
F & 0 & AS & $10274 \pm 2460$ & 0 & 0 \\
F & 1 & 0 & $84825 \pm 2148$ & $501 \pm 28$ & $581 \pm 110$ \\
F & 1 & MS & $84427 \pm 1473$ & $493 \pm 10$ & $655 \pm 13$ \\
F & 1 & AS & $80178 \pm 1430$ & $768 \pm 19$ & $698 \pm 32$ \\
& & & & & \\
\hline
\end{tabular}

* Low density bone marrow cells. $\quad{ }^{\ddagger}$ Bone marrow-derived fibroblasts.

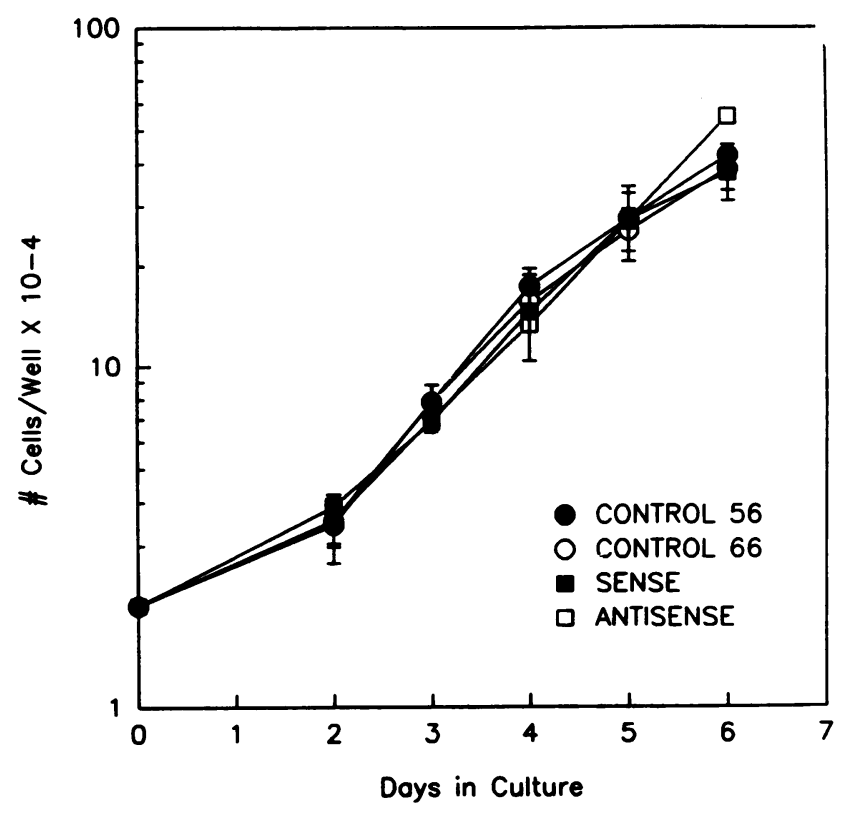

Figure 4. Antisense FACC ODN does not inhibit growth of human diploid (11-Lu) fibroblasts. Subconfluent cells were exposed to antisense or sense ODN for $24 \mathrm{~h}$, complete medium was replaced, and viable cells were counted on days $2-6$. Cells not exposed to ODN were exposed to medium containing heat-inactivated $\left(56^{\circ} \mathrm{C}\right) \mathrm{FCS}(\mathrm{CON}$ TROL 56) or high-heat $\left(66^{\circ} \mathrm{C}\right)$ inactivated FCS (CONTROL 66) for 24 h. ODN exposure was in high-heat-inactivated FCS. Data points represent means \pm SD of counts on duplicate wells.

known FACC mutation. Establishing the exact role of the FACC protein in normal cells will require a broad-based search. It may play a role in growth factor signal transduction or, alternatively, might function to suppress either a mitotic inhibitory pathway or apoptosis in progenitor cells.

Although growth of fibroblasts, mitogen-stimulated lymphocytes, and endothelial cells was not affected by exposure to the antisense ODN (Fig. 4 and data not shown), we have not yet tested a sample of nonhematopoietic cell types large enough to suggest that this particular role of the FACC gene product is strictly specific to hematopoietic cell types. However, discovery of additional roles of this protein in growth, differentiation, or survival of other cell populations will in no way diminish the likelihood that the FACC protein plays a biologically significant hematopoietic role. Other proteins, such as Steel factor, with unambiguous hematopoietic function in vivo (36-39), also play functional roles in nonhematopoietic cells (40-43). The specific loss-of-function approach described here will permit a more specific clarification of the precise role of the FACC gene product in growth and development of both hematopoietic and nonhematopoietic cells.

\section{Acknowledgments}

This work was supported in part by grants from the National Institutes of Health (CA-36306 to G. C. Bagby, Jr. and DK-43375 to G. M. Segal), the Department of Veterans Affairs (M. C. Heinrich and G. C. Bagby, Jr.), and the Henry M. and Lillian Stratton Foundation (G. M. Segal). 


\section{References}

1. Schroeder, T. M., D. Tilgen, J. Kruger, and F. Vogel. 1976. Formal genetics of Fanconi's anemia. Hum. Genet. 32:257-288.

2. Auerbach, A. D., and R. G. Allen. 1991. Leukemia and preleukemia in Fanconi anemia patients: a review of the literature and report of the International Fanconi Anemia Registry. Cancer Genet. Cytogenet. 51:1-12.

3. Auerbach, A. D., B. Adler, and R. S. Chaganti. 1981. Prenatal and postnatal diagnosis and carrier detection of Fanconi anemia by a cytogenetic method. Pediatrics. 67:128-135.

4. Auerbach, A. D., A. Rogatko, and T. M. Schroeder-Kurth. 1989. International Fanconi Anemia Registry: relation of clinical symptoms to diepoxybutane sensitivity. Blood. 73:391-396.

5. Strathdee, C. A., A. M. V. Duncan, and M. Buchwald. 1992. Evidence for at least four Fanconi anaemia genes including FACC on chromosome 9. Nature Genet. 1:196-198.

6. Strathdee, C. A., H. Gavish, W. R. Shannon, and M. Buchwald. 1992.

Cloning of cDNAs for Fanconi's anaemia by functional complementation. Nature (Lond.). 356:763-767.

7. Strathdee, C. A., H. Gavish, W. R. Shannon, and M. Buchwald. 1992. Erratum: cloning of cDNAs for Fanconi's anaemia by functional complementation. Nature (Lond.). 358:434.

8. Sun, Y., and R. E. Moses. 1991. Reactivation of psoralen-reacted plasmid DNA in Fanconi anemia, xeroderma pigmentosum, and normal human fibroblast cells. Somatic Cell Mol. Genet. 17:229-238.

9. Gavish, H., C. C. dos Santos, and M. Buchwald. 1993. A Leu554-to-Pro substitution completely abolishes the functional complementing activity of the Fanconi anemia (FACC) protein. Hum. Mol. Genet. 2:123-126.

10. McCall, E., and G. C. Bagby. 1985. Monocyte-derived recruiting activity. Kinetics of production and effects of endotoxin. Blood. 65:689-695.

11. Segal, G. M., T. Smith, M. C. Heinrich, F. S. Ey, and G. C. Bagby 1992. Specific repression of granulocyte-macrophage and granulocyte colonystimulating factor gene expression in interleukin-1-stimulated endothelial cells with antisense oligodeoxynucleotides. Blood. 80:609-616.

12. Cervenka, J., and B. A. Hirsch. 1983. Cytogenetic differentiation of Fanconi anemia, "idiopathic" aplastic anemia, and Fanconi anemia heterozygotes Am. J. Med. Genet. 15:211-223.

13. Hungerford, D. A. 1965. Leukocytes cultured from small inocula of whole blood and the preparation of metaphase chromosomes by treatment with hypotonic KCl. Stain Technol. 40:333-378.

14. Segal, G. M., E. McCall, T. Stueve, and G. C. Bagby. 1987. Interleukin 1 stimulates endothelial cells to release multilineage human colony-stimulating activity. J. Immunol. 138:1772-1778.

15. Tso, J. Y., X. H. Sun, T. H. Kao, K. S. Reece, and R. Wu. 1985. Isolation and characterization of rat and human glyceraldehyde-3-phosphate dehydrogenase cDNAs: genomic complexity and molecular evolution of the gene. Nucleic Acids Res. 13:2485-2502.

16. Lee, M., G. M. Segal, and G. C. Bagby. 1987. Interleukin-1 induces human bone marrow-derived fibroblasts to produce multilineage hematopoietic growth factors. Exp. Hematol. (NY). 15:983-988.

17. Bagby, G. C., E. McCall, K. A. Bergstrom, and D. Burger. 1983. A monokine regulates colony-stimulating activity production by vascular endothelial cells. Blood. 62:663-668.

18. Zsebo, K. M., V. Yuschenkoff, S. Schulter, D. Chong, E. McCall, C. A. Dinarello, B. Altrock, and G. C. Bagby. 1988. Vascular endothelial cells and granulopoiesis: interleukin-1 stimulates release of G-CSF and GM-CSF. Blood. 71:99-103.

19. Maciag, T., T. Mehlman, R. Friesel, and A. Schreiber. 1984. Heparin binds endothelial cell growth factor, the principal endothelial cell mitogen in bovine brain. Science (Wash. DC). 225:932-935.

20. Alter, B. P., M. E. Knobloch, and R. S. Weinberg. 1991. Erythropoiesis in Fanconi's anemia. Blood. 78:602-608.

21. Schindler, D., and H. Hoehn. 1988. Fanconi anemia mutation causes cellular susceptibility to ambient oxygen. Am. J. Hum. Genet. 43:429-435.
22. Gille, J. J., H. M. Wortelboer, and H. Joenje. 1987. Antioxidant status of Fanconi anemia fibroblasts. Hum. Genet. 77:28-31.

23. Okumura, N., K. Tsuji, and T. Nakahata. 1992. Changes in cell surface antigen expression during proliferation and differentiation of human erythroid progenitors. Blood. 80:642-650.

24. Segal, G. M., and G. C. Bagby. 1991. Identification of sensitive mRNA target sites for selective inhibition of granulocyte-macrophage colony-stimulating factor (GM-CSF) and granulocyte colony-stimulating factor (G-CSF) gene expression by antisense oligonucleotides (ODNs). Clin. Res. 39:209a.(Abstr.)

25. Alter, B. P. 1992. Leukemia and preleukemia in Fanconi's anemia. Cancer Genet. Cytogenet. 58:206-208.

26. Auerbach, A. D. 1992. Fanconi anemia and leukemia: tracking the genes. Leukemia (Baltimore). 6(Suppl. 1):1-4.

27. Berger, R., M. Le Coniat, and G. Schaison. 1993. Chromosome abnormalities in bone marrow of Fanconi anemia patients. Cancer Genet. Cytogenet. 65:4750.

28. Stark, R., D. Thierry, P. Richard, and E. Gluckman. 1993. Long-term bone marrow culture in Fanconi's anaemia. Br. J. Haematol. 83:554-559.

29. Rosselli, F., J. Sanceau, J. Wietzerbin, and E. Moustacchi. 1992. Abnormal lymphokine production: a novel feature of the genetic disease Fanconi anemia. I. Involvement of interleukin-6. Hum. Genet. 89:42-48.

30. Bagby, G. C., G. M. Segal, A. D. Auerbach, T. Onega, W. Keeble, and M. C. Heinrich. 1993. Constitutive and induced expression of hematopoietic growth factor genes by fibroblasts from children with Fanconi's anemia. Exp. Hematol. (NY). 21:1419-1426.

31. Dash, P., I. Lotan, M. Knapp, E. R. Kandel, and P. Goelet. 1987. Selective elimination of mRNAs in vivo: complementary oligodeoxynucleotides promote RNA degradation by an RNase H-like activity. Proc. Natl. Acad. Sci. USA. 84:7896-7900.

32. Walder, R. Y., and J. A. Walder. 1988. Role of RNase $\mathrm{H}$ in hybridarrested translation by antisense oligonucleotides. Proc. Natl. Acad. Sci. USA. 85:5011-5015.

33. Bennett, R. M. 1993. As nature intended? The uptake of DNA and oligonucleotides by eukaryotic cells. Antisense Res. Dev. 3:235-241.

34. Krieg, A. M., F. Gmelig-Meyling, M. F. Gourley, W. J. Kisch, L. A. Chrisey, and A. D. Steinberg. 1991. Uptake of oligodeoxyribonucleotides by lymphoid cells is heterogeneous and inducible. Antisense Res. Dev. 1:161-171.

35. Walsh, C. E., M. Grompe, N. S. Young, A. W. Nienhuis, and J. M. Liu. 1993. A functionally active retrovirus vector for gene therapy in Fanconi's anemia type C. Blood. 82:176a. (Abstr.)

36. Flanagan, J. G., D. C. Chan, and P. Leder. 1991. Transmembrane form of the kit ligand growth factor is determined by alternative splicing and is missing in the $S l^{d}$ mutant. Cell. 64:1025-1035.

37. Brannan, C. I., S. D. Lyman, D. E. Williams, J. Eisenman, D. M. Anderson, D. Cosman, M. A. Bedell, N. A. Jenkins, and N. G. Copeland. 1991. Steel-Dickie mutation encodes a c-kit ligand lacking transmembrane and cytoplasmic domains. Proc. Natl. Acad. Sci. USA. 88:4671-4674.

38. Migliaccio, A. R., G. Migliaccio, B. Durand, G. Mancini, and J. W. Adamson. 1993. The generation of colony-forming cells (CFC) and the expansion of hematopoiesis in cultures of human cord blood cells is dependent on the presence of stem cell factor (SCF). Cytotechnology. 11:107-113.

39. McNiece, I. K., K. E. Langley, and K. M. Zsebo. 1991. Recombinant human stem cell factor synergises with GM-CSF, G-CSF, IL-3 and Epo to stimulate human progenitor cells of the myeloid and erythroid lineages. Exp. Hematol. (NY). 19:226-231.

40. Pesce, M., M. G. Farrace, M. Piacentini, S. Dolci, and M. De Felici. 1993. Stem cell factor and leukemia inhibitory factor promote primordial germ cell survival by suppressing programmed cell death (apoptosis). Development (Camb.). 118:1089-1094.

41. Williams, D. E., P. deVries, A. E. Namen, M. B. Widmer, and S. D. Lyman. 1992. The Steel factor. Dev. Biol. 151:368-376.

42. Rossi, P., C. Albanesi, P. Grimaldi, and R. Geremia. 1991. Expression of the mRNA for the ligand of c-kit in mouse Sertoli cells. Biochem. Biophys. Res. Commun. 176:910-914.

43. Murphy, M., K. Reid, D. E. Williams, S. D. Lyman, and P. F. Bartlett. 1992. Steel factor is required for maintenance, but not differentiation, of melanocyte precursors in the neural crest. Dev. Biol. 153:396-401. 